\title{
Spatial Distribution and Temporal Variation of Solar UV Radiation over the Tibetan Plateau
}

\author{
Gelsor Norsang (Corresponding author) \\ Geophysics Institute, Tibet University \\ Jiangsu Rd.36, Lhasa, Postcode 850000, Tibet, P.R.C, China \\ Tel: 86-135-4907-6665 E-mail: norsang2@gmail.com \\ Ladislav Kocbach \\ Department of Physics and Technology, University of Bergen \\ All'egaten 55, N-5007, Bergen, Norway \\ Tel: 47-5558-2870 E-mail: ladi@post.fi.uib.no
}

\author{
Jakob Stamnes \\ Department of Physics and Technology, University of Bergen \\ All'egaten 55, N-5007, Bergen, Norway \\ Tel: 47-5558-2818 E-mail: jakobj.stamnes@fi.uib.no \\ Wangmu Tsoja \\ Geophysics Institute, Tibet University \\ Jiangsu Rd.36, Lhasa, Postcode 850000, Tibet, P.R.C, China \\ Tel: 86-136-3899-9941_E-mail: tsoja2@yahoo.com \\ Nima Pincuo \\ Geophysics Institute, Tibet University \\ Jiangsu Rd.36, Lhasa, Postcode 850000, Tibet, P.R.C, China \\ Tel: 86-158-8901-7289 E-mail: Pingcuo.Nima@student.uib.no
}

Received: September 29, $2010 \quad$ Accepted: October 11, 2010 doi:10.5539/apr.v3n1p37

The research is financed by the National Natural Science Foundation of China (Project code: 41065009) and the Network for University Cooperation Tibet-Norway. The Earth Probe TOMS data were provided by $N A S D A / G S F C$.

\begin{abstract}
The Tibetan Plateau has very high levels of ultraviolet radiation. To study the UV radiation across the Tibetan Plateau, data from the TOMS (Total Ozone Mapping Spectrometer) satellite for the periods 1979 -1992 and 1997- 2003 are used. The analysis shows a 21-year average of the spatial distribution of daily summer erythemal UV doses across the Tibetan Plateau and its vicinity with a spatial resolution of $1^{\circ}$ Lat. - $1.25^{\circ}$ Long., also obtains temporal variations during the period 1979 - 2003 of UV radiation for the region by selecting seven locations across the Tibetan Plateau and its neighboring areas. The results show that during the summer months from May to August the average daily erythemal UV doses at the selected seven sites across the Tibetan Plateau range from 7.5 to $9.0 \mathrm{~kJ} / \mathrm{m} 2$. These daily erythemal UV doses are considerably higher than those observed at
\end{abstract}


geographically close, lower-altitude locations such as Chengdu in China and New Delhi in India, which had corresponding values of $4.1 \mathrm{~kJ} / \mathrm{m} 2$ and $5.8 \mathrm{~kJ} / \mathrm{m} 2$, respectively. During the period from 1979 to 1992 observe a clear trend of increasing erythemal UV doses over the Tibetan Plateau. Comparisons between satellite derived UV radiation and ground-based measurements of UV radiation for Lhasa are made.

Keywords: Tibetan Plateau, UV spatial distribution, Daily erythemal UV dose, TOMS satellites

\section{Introduction}

Quantification of local erythemal (McKinlay and Diffey, 1987) UV radiation levels is important for studies of biological, environmental, and human health effects of UV radiation (Diaz et al., 2001; Kripke, 1990; Reichrath et al., 2008). We examine levels of UV radiation across the Tibetan Plateau, the highest plateau in the world. The plateau is characterized by a highly intense solar radiation and a particularly high UV radiation component (Dahlback et al., 2007). Due to the combined effects of high altitude, thin air (60-70\% air pressure compared to that at sea level), low ozone concentration (Zou and Gao,1997), and low latitude $\left(27^{\circ} \mathrm{N}-39^{\circ} \mathrm{N}\right)$, the surface UV radiation levels across the Tibetan Plateau are among the highest in the world during the summer months.

\subsection{Altitude Effect on Surface UV}

Many factors, including latitude, sky conditions, surface conditions, time of the year, and total ozone column amount (TOCA) in the atmosphere, determine the amount of surface UV radiation at a given geographical location (McKenzie et al., 1998; Madronich, 1993). If all other conditions are the same, the altitude impact on the surface UV radiation is significant. Lhasa in Tibet, Chengdu in China, and New Delhi in India are located at similar latitudes, ranging from $28.67^{\circ} \mathrm{N}$ to $31.1^{\circ} \mathrm{N}$. However, Lhasa, which is the higher and drier of these three places, receives an average summer daily erythemal UV dose that is about twice as large as that received in Chengdu or New Delhi. UV radiation is also absorbed by tropospheric ozone in the lower atmosphere (Brühl and Crutzen, 1989). At mid-latitudes in the northern hemisphere, a typical vertical profile of ozone shows that the total ozone column amount decreases rapidly with increasing altitude until an altitude of about $7 \mathrm{~km}$ above the sea level. Therefore, the higher the altitude, the lower the total ozone column amount, and the higher the UV radiation level at the surface. On the other hand, UV is scattered by clouds, water vapor, dust particles, and air molecules (Liu et al., 1991). For a clear sky, UV radiation may be significantly attenuated by Rayleigh scattering, since the scattering cross-section is inversely proportional to the fourth power of the wavelength. But UV radiation is also subjected to Mie scattering by water droplets (clouds), pollen, dust, smoke, and other particles in the lower part of the atmosphere. Thus, the higher the altitude, the dryer and cleaner the air with less scattering particles, the higher the UV radiation levels at the surface. This also implies that at higher altitudes there is more direct UV radiation than at the sea level, where there are about equal amounts of direct and diffuse UV radiation. As a general consequence of this, for every $1 \mathrm{~km}$ increase in altitude the UV level may increase by approximately 7 - 9\% (Dahlback et al., 2007)

\subsection{Ground-based UV Measurements in Tibet}

Ground-based instruments are best suited for measuring the UV radiation that reaches the surface of the Earth at a particular location. Compared to ground-based instruments, satellite instruments for measuring UV radiation have the advantages that they cover large areas of the surface simultaneously and provide access to remote areas that can not easily be reached at the ground. Thus, with satellite instruments one can obtain a cost-effective monitoring of UV radiation levels and total ozone column amounts covering most places on the Earth's surface. Satellite remote sensing is particularly useful at remote sites where natural conditions make access for ground measurements difficult.

In this paper we investigate the consistency of two types of UV radiation data for Lhasa in Tibet by comparing ground-measured UV levels with corresponding satellite-estimated values for the spring and summer months of 2003.

The ground-based UV measurements were carried out at the Solar UV and Ozone Observatory at Tibet University in Lhasa. Multi-channel moderate bandwidth filter NILU-UV irradiance meters (Høiskar et al., 2003) manufactured by the Norwegian Institute for Air Research (NILU AS, http://uv.nilu.no) were used to measure the total incoming irradiance in five channels across the UV spectral range with center wavelengths at $305 \mathrm{~nm}, 312$ $\mathrm{nm}, 320 \mathrm{~nm}, 340 \mathrm{~nm}$, and $380 \mathrm{~nm}$. The Full Width at Half Maximum (FWHM) of each channel is about $10 \mathrm{~nm}$. Instruments such as these require accurate calibrations. Teflon diffusers are placed in front of the filters to obtain the global radiation. The algorithm used to derive UV radiation levels and total ozone column amounts from NILU-UV instrument recordings is given in (Dahlback 1996).

The NILU-UV meter was calibrated against a reliable Bentham spectroradiometer at the Norwegian Radiation 
Protection Authoroty (NRPA), Norway in 2003.

\subsection{Derivation of TOMS Daily Erythemal UV Doses}

The TOMS (http://toms.gsfc.nasa.gov/; McPeters et al., 1996; McPeters et al., 1998) daily erythemal UV dose is derived from measurements during the satellite overpass. According to TOMS erythemal data products (ftp://jwocky.gsfc.nasa.gov/pub/eptoms/data/erynotes.pdf), the TOMS surface daily erythemal UV dose is given by

$$
E_{x p .}=\frac{1}{d_{e s}^{2}} \int_{280 n m}^{400 n m} d \lambda S(\lambda) W(\lambda) \int_{t_{s r}}^{t_{s s}} d t C\left(\lambda, \theta, \tau_{c l}\right) F(\lambda, \theta, \Omega)
$$

Here $_{W(\lambda)}$ is the CIE weighting function and it is given by

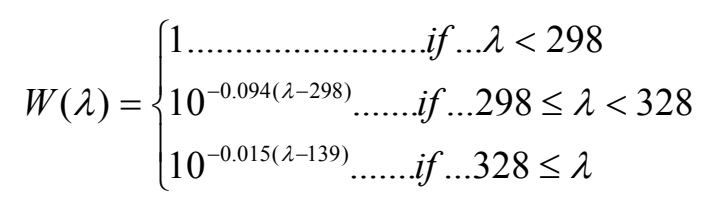

$W(\lambda)$ is used as the biological action spectrum. The Earth-Sun distance $d_{e s}$ (in A.U.), the sunrise time $t_{s r}$, the sunset time $t_{s s}$, and the solar zenith angle $\theta$ are calculated from standard formulas at any given location. The solar irradiance $S(\lambda)$ incident at the top of the atmosphere when the Earth is at a distance of 1 A.U. from the Sun, has been measured by satellite instruments (Woods et al., 1996). Given the total ozone column amount $\Omega$ measured by TOMS, the wavelength $\lambda$, and the solar zenith angle $\theta$, the spectral irradiance $F(\lambda)$ (normalized to a maximum value of unity at the top of the atmosphere) at the surface for a clear sky condition is computed using tabulated solutions of the radiative transfer equation. The cloud attenuation factor $C\left(\lambda, \theta, \tau_{c l}\right)$ in (1) is obtained by first computing a cloud optical thickness $\tau_{c l}$, and then computing the attenuation of the global irradiance due to a uniform cloud of optical thickness $\tau_{c l}$. A detailed description of the UV mapping algorithm is given in the TOMS Data Products User's Guide.

The global UV data sets used in the present work have been very useful for documenting the annual variability of the UV radiation and for detecting trends on a large spatial scale. However, uncertainties caused by drift in the TOMS instrument, data processing errors, and calibration errors may be present in the data. During our research period we found a number of random data errors, e.g. impossibly large data values did occasionally occur. In such cases, the erroneous data were replaced by averages of previous and subsequent data. This procedure was found to be acceptable for making long-term averages. According to the TOMS erythemal data products notes (ftp://jwocky.gsfc.nasa.gov/pub/eptoms/data/erynotes.pdf), the EP/TOMS total ozone column amount has an absolute error of $3 \%$, a random error of $2 \%$ (although these errors are somewhat higher at high latitudes), and a drift after 1.5 years of operation of less than $0.6 \%$. Satellites measuring UV radiation and ozone pass over a given location once a day. The computed cloud optical thickness $\tau_{c l}$ is assumed to be valid throughout the day. This assumption may lead to large discrepancies between UV radiation exposures derived from TOMS data and ground based measurements. By taking a sufficiently long time average, one may reduce this error. In high-altitude regions with a high surface reflectivity the TOMS UV algorithm tends to overestimate the UV exposure.

Nevertheless, comparisons reported in the literature for the northern hemisphere of TOMS derived UV radiation data with those obtained from ground-based measurements have shown that the use of TOMS data to derive daily, monthly or annual erythemal UV doses at most places on Earth is accurate enough for most medical or biological applications.

\section{Results and Discussion}

\subsection{Comparison between Satellite (EP/TOMS) Estimated and Ground-Measured UV radiation data for Lhasa in Tibet}

The use of satellite and ground-based data has a complementary effect on the observation of variations in UV radiation and total ozone column amount. The TOMS daily erythemal UV dose represents an average for each day over a certain area (the TOMS instrument makes 35 measurements every 8 seconds, each covering around 50-200 km of the Earth's surface) and is determined from the satellite overpass information. In contrast, ground-based UV radiation measurements, which provide a higher temporal resolution during a day at one specific location, are sensitive to variations in the cloud structure and the surface albedo, and also to obstructions that may block a part of the incoming radiation. Therefore, the UV radiation values derived from these two 
different measurements will never agree perfectly. Fig.1 shows comparisons between ground-measured and EP/TOMS-derived erythemal UV doses for Lhasa in 2003.

The daily erythemal UV doses for a clear-sky atmosphere are about $13.0 \%$ higher (on the average) than the corresponding values measured on the ground. We also found that the TOMS-derived monthly average of the daily erythemal UV dose in Lhasa for 2003 is higher than the ground-measured UV dose by about $17.0 \%$ (on the average). In addition to the error sources mentioned above, these differences may be due to:

- The tendency to overestimate UV exposures at high altitudes as mentioned in the TOMS Data User's Guide.

- Small drift of the NILU-UV instrument. We detected small drifts in some of the channels of the instrument. Drift correction was made by increasing the daily erythemal UV dose by about 3-6\% for some of the months, but this correction may not have been sufficient.

- Observation conditions. The instrument in Lhasa was mounted at the top of a building that is surrounded by high mountains. The nearest mountains are about five kilometers to the south of the building. This natural obstruction may contribute some part of the causes.

\subsection{Spatial Distribution of Summer Erythemal UV dose across the Tibetan Plateau}

We used NIMBUS-7/TOMS and EP/TOMS daily erythemal UV data for the periods1979 -1992 and 1997 2003, determined a 21-year average of the spatial distribution of daily erythemal UV doses across the Tibetan Plateau and its vicinity, which is important for studies of environmental, and human health effects of UV radiation. The daily erythemal UV doses at any point at the Tibetan Plateau and its vicinity with a spatial resolution of $1^{\circ}$ Latitude $-1.25^{\circ}$ Longitude are clearly shown in a 3D color map in Fig.2 and 2D color map in Fig.3(a). Both figures (made from a same data) show that the daily erythemal UV doses at the Tibetan Plateau are considerably higher than those observed at geographically close, but lower-altitude locations. The summer mean daily erythemal UV dose exceeds about $6.0 \mathrm{~kJ} / \mathrm{m}^{2}$ over the whole Tibetan Plateau. Extremely high summer erythemal UV doses (above $8.0 \mathrm{~kJ} / \mathrm{m}^{2}$ ) have been found to occur in some areas (see Fig.2) at the Tibetan Plateau:

- In the eastern part of the Tibetan Plateau, in the Chamdo region;

- In the middle of the Tibetan Plateau, in the Lhasa and Nagqu regions;

- In the western part of the Tibetan Plateau along the northern side of Himalaya mountains;

- Very high erythemal UV doses, above $7.0 \mathrm{~kJ} / \mathrm{m}^{2}$ occur in the most populated areas at the plateau during the summer. The corresponding values for the neighboring lower-altitude areas, such as New Dehli in India and Chengdu in China are only $5.8 \mathrm{~kJ} / \mathrm{m}^{2}$ and $4.1 \mathrm{~kJ} / \mathrm{m}^{2}$, respectively.

The altitude effect on the UV radiation is reflected in Fig.2 and Fig.3(a). Fig.3(b) shows an elevation contour map of the Tibetan Plateau obtained by using high-resolution elevation data from the Global Elevation Dataset, TerrainBase (Terrain Base). By comparing Fig.3(a) and Fig.3(b), we clearly see the altitude effect on the UV radiation. For the most areas, the higher the altitude the higher the UV level. The elevation map in Fig.3(b) is roughly reflected in the UV radiation map in Fig.3(a). In the TOMS UV radiation dataset, a nominal increase of $6 \%$ per kilometer increase in altitude was employed to estimate exposure levels for areas above the sea level. The grid coordinates in Fig.3(a) and Fig.3(b) represent latitude and longitude. International border lines are shown in yellow, and major cities are also shown. The Tibetan Plateau is located between about $28^{\circ}-39^{\circ} \mathrm{N}$ and $77^{\circ}-102^{\circ}$ E. The daily erythemal UV dose is given in $\mathrm{kJ} / \mathrm{m}^{2}$. The color bar in Fig.3(a) shows the erythemal UV dose level in $\mathrm{kJ} / \mathrm{m}^{2}$. The color bar in Fig.3(b) shows the altitude in meters. The spatial distribution of the multi-year average of the summer mean daily erythemal UV dose is illustrated in Fig.3(a). The daily erythemal UV dose received in the most populated areas in Tibet, including all major towns (except Ngintri), is above 7.0 $\mathrm{kJ} / \mathrm{m}^{2}$, as shown by the yellow and red patches in Fig.3(a).

Extremely high UV doses above $8.0 \mathrm{~kJ} / \mathrm{m}^{2}$ occur in the higher-altitude areas in the northern part of the west Himalayan mountains, which are mainly in the western part of Tibet. The highest UV dose reaches $9.1 \mathrm{~kJ} / \mathrm{m}^{2}$ in the area about $30.5^{\circ} \mathrm{N}$ and $85^{\circ} \mathrm{E}$.

Weather conditions may affect the average UV radiation level significantly. We found the summer mean daily erythemal UV dose for the Mt. Everest area to be only about $7.0 \mathrm{~kJ} / \mathrm{m}^{2}$. However, the instantaneous erythemal UV dose rate in this area may be the highest in the world during the summer. The Himalayas, including Mt. Everest, represent the climatic boundary between a region dominated by the influence of the Indian summer monsoon to the South and the relatively dry continental climate to the North on the Tibetan Plateau. This may be one of the main reasons why the extremely high UV radiation levels (with daily erythemal UV doses above 8.0 
$\mathrm{kJ} / \mathrm{m}^{2}$ ) occur to the North of the boundary, inside the Tibetan region shown as a red patch in Fig.3(a). The annual total solar irradiances in this region are the highest in the Tibetan Plateau.

The Earth's surface conditions also affect the level of the UV radiation. Generally, snow and ice reflect more than $70 \%$ of the UV radiation, whereas bare ground and sand reflect only about $15 \%$. Grass, soil, and water reflect less than $10 \%$. The ground surface of the Tibetan Plateau is partly snow covered, partly rocky mountains, and partly bare ground in the western part of Tibet, from a longitude of about $77^{\circ} \mathrm{E}$ to about $87^{\circ} \mathrm{E}$. The high UV radiation levels in this region are probably caused by the combined effects of altitude, surface reflection enhancement, and sunny weather. But the high UV levels derived from satellite data could also be caused by the tendency to overestimate, as mentioned earlier. At the south-eastern edges of the Tibetan Plateau, more grassland appears giving a lower surface reflection, which may make the UV radiation levels decrease in these regions.

\subsection{Temporal Variations of Erythemal UV Dose across the Tibetan Plateau}

The time of the year affects the level of the UV radiation tremendously. We studied temporal variations of daily UV doses over the Tibetan Plateau and its neighboring areas.

\subsubsection{Temporal variation of daily erythemal UV dose for Lhasa}

Fig.3(a) and Fig.3(b) show that the Lhasa region, which is the most populated area in Tibet, has a vary high UV radiation exposure in the summers. Fig.4 shows multi-year (1980-1992 and 1997-2003) averages of monthly mean daily erythemal UV doses in Lhasa. It exhibits a typical monthly variation of the erythemal UV dose at one point on the Tibetan Plateau, showing that the amount of UV radiation varies significantly with month and season. During the summer the UV radiation level is more than three times higher than during the winter. During the summer (May - August) the average daily erythemal UV dose in Lhasa exceeds $6.0 \mathrm{~kJ} / \mathrm{m}^{2}$, and it reaches a peak in June of about $8.5 \mathrm{~kJ} / \mathrm{m}^{2}$.

\subsubsection{Temporal variations of UV radiation over the plateau in the summers}

At the Tibetan Plateau plants and trees are budding and opening new leaves during the period from May to July, it is the best season for the tourists too. A high UV radaiton may be harmful both to the new life and new people, unless the organisms and people are able to adapt to the environment. We selected the three summer months of May, June, and July to show the temporal variation in the UV radiation at the Tibetan Plateau in this particular season. Fig.5(May, June, July) illustrates the monthly variation of the UV radiation at any location on the Tibetan Plateau and in its neighboring lower-altitude areas during the three summer months. The figures show a significant UV variation from one month to another in most areas of the Tibetan Plateau. The regions with highest UV radiation are shown as dark red patches. They receive a daily erythemal UV dose above $9.0 \mathrm{~kJ} / \mathrm{m}^{2}$. The red patches represent areas that receive a daily erythemal UV dose above $8.0 \mathrm{~kJ} / \mathrm{m}^{2}$, and yellow patches represent areas that receive a daily erythemal UV dose above $7.0 \mathrm{~kJ} / \mathrm{m}^{2}$. These $2 \mathrm{D}$ color maps show that in certain areas of the Tibetan Plateau, the dark red areas get larger and larger from May to July, get maximum in July.

\subsubsection{Long-term variations of UV radiation for some selected towns}

We also analyzed long-term summer erythemal UV doses at some selected places across the Tibetan Plateau and its vicinity to determine the variations in the average daily UV dose for 21 summers in the period from 1979 to 2003 (Note that for the years from 1993 to 1996 there are not sufficient satellite data available). Fig.6 shows a long-term variations of averaged daily erythemal UV doses at the seven selected. We see that the three locations, Lhasa, Nagqu, and Chamdo at the heart of the Tibetan Plateau have very similar fluctuation variations from year to year. There is a clear trend from 1980 to around 1992 of an increasing level of the UV radiation. During this period the summer average daily erythemal UV dose in Lhasa, Chamdo, and Nagqu increased by respectively $1.69 \%, 1.18 \%$, and $0.67 \%$ per year. For Senge Khabob the corresponding increase was only $0.35 \%$. However, for the neighboring lower-altitude areas there is no significant trend. Fig.6 also shows that the summer UV radiation at the Tibetan Plateau is much higher than at the surrounding lower-altitude areas for all years.

Except the other factors of controlling surface UV levels, ozone may play very sensitive role to the UV level (WMO, 1998). A so called "ozone valley" (Liu et al.,2003) over the Tibetan Plateau in summer was found. The TOCAs across the Tibetan Plateau are much lower than across the neighboring lower-altitude areas, this may be one of reasons why the UV levels are much higher at the Tibetan Plateau than that of others. However, we note that recently signs of a global ozone recovery were reported based on satellite data analyses (Newchurch et al., 2003). Additional comments on this issue are beyond the scope of this paper. 


\section{Conclusions}

For the first time, spatial distributions of solar UV radiation over the Tibetan Plateau and its vicinity have been studied. Spatially resolved maps of multi-year averaged summer mean daily erythemal UV dose are obtained, which may provide more accurate information for UV climatology over that region where very limited studies on the subject had been curried out. The Tibetan Plateau receives extremely high level of daily erythemal UV doses in the summers, the average may range from about $6.0 \mathrm{~kJ} / \mathrm{m}^{2}$ to $9.1 \mathrm{~kJ} / \mathrm{m}^{2}$. For those in neighboring areas at lower altitudes, the averages are bellow $6.0 \mathrm{~kJ} / \mathrm{m}^{2}$. Extremely high (above $8.0 \mathrm{~kJ} / \mathrm{m}^{2}$ ) daily erythemal UV doses do occur in some places in July, particularly. Erythemal UV dose level above $7.0 \mathrm{~kJ} / \mathrm{m}^{2}$ occur in the most populated areas too.

The high altitude, low TOCA, reflective surface and thin air etc. may play great role for the high level of UV radiation over the Tibetan Plateau.

Temporal variations of summer mean daily erythemal UV doses for the 21 years are discussed. An increasing trend in the daily erythemal UV dose during 1980 to 1992 for the Tibetan Plateau was found. E.g. Lhasa increased by $1.69 \%$ per year. There was no significant increase from 1997 to 2003 . UV level over the Tibetan Plateau seems very sensitive to TOCA, the temporal fluctuation in the UV radiation is anti-correlated with the fluctuation in the TOCA.

The comparison between satellite derived UV radiation and ground-based measurements indicates that the monthly average of the daily erythemal UV dose in Lhasa is higher than the ground-measured by about $17.0 \%$. The daily erythemal UV doses for a clear-sky are about $13.0 \%$ higher than the corresponding values measured on the ground.

\section{References}

Brühl, C. and P. J. Crutzen. (1989). On the Disproportionate Role of Tropospheric Ozone as a Filter Against Solar UV-B Radiation. Geophysical Research Letters. Vol. 16, pp. 703-706.

Dahlback, A. (1996). Measurements of biologically effective UV doses, total ozone abundances, and cloud effects with multichannel, moderate bandwidth filter instruments. Appl. Opt. 35, 6514-6521.

Dahlback, A., G. Norsang, J. J. Stamnes, and Y. Gjessing. (2007). UV Measurements in the 3000-5000 Meter Altitude Region In Tibet. J. Geophys. Res., 112, D09308, doi:10.1029/2006JD007700 (2007).

Diaz, S., G. Deferrari, C.R. Booth, D. Martinioni and A. Oberto. (2001). Solar irradiances over Ushuaia $\left(54.49^{\circ}\right.$ S, $\left.68.19^{\circ} \mathrm{W}\right)$ and San Diego $\left(32.45^{\circ} \mathrm{N}, 117.11^{\circ} \mathrm{W}\right)$ geographical and seasonal variation. Journal of Atmospheric and Solar Terrestrial Physics. 63 (4) (2001), pp. 309-320.

Høiskar, B. A. K., R. Haugen, T. Danielsen, A. Kylling, K. Edvardsen, A. Dahlback, B. Johnsen, M. Blumthaler, and J. Schreder. (2003). Multichannel moderate-bandwidth filter instrument for measurement of the ozone-column amount, cloud transmittance, and ultraviolet dose rates. Appl. Opt. 42, 3472-3479.

Kripke, M.L. (1990). Effects of UV radiation on tumor immunity. J Natl Cancer Inst., 82, No 17:1392-1396.

Liu, S. C., S. A. McKeen, and S. Madronich. (1991). Effect of Anthropogenic Aerosols on Biologically Active Ultraviolet Radiation. Geophysical Research Letters, Vol. 18, pp. 2265-2268.

Liu, Y., Li, W., Zhou, X.J and J.H, He. (2003). Mechanism of Formation of the Ozone Valley over the Tibetan Plateau in Summer Transport and Chemical Process of Ozone. Advances in Atmospheric Sciences. Vol. 20 No.1, pp.103-109.

Madronich, S. (1993). UV Radiation in the natural and perturbed atmosphere. In: M. Tevini, Editor, UV-B Radiation and Ozone Depletion, Effects on Humans, Animals, Plants, Microorganisms, and Materials. Lewis Publishers. USA (1993), pp. 17-69.

McKenzie, R.L., Paulin, K.J. and Madronich, S. (1998). Effects on snow cover on UV irradiance and surface albedo: a case study. Journal of Geophysical Research. 22, pp. 28,785-28,792.

McKinlay, A.F. and B.L. Diffey. (1987). A reference action spectrum for ultraviolet induced erythema in human skin. CIE Journal (6) (1987). pp. 17-22.

McPeters, R.D. P. K., Bhartia, A. J. Krueger, and J. R. Herman. (1998). Earth Probe Total Ozone Mapping Spectrometer (TOMS), Data Products User's Guide. NASA Technical Publication 1998-206895, NASA/Goddard Space Flight Center, Greenbelt, MD 20771. 
McPeters, R.D., P. K. Bhartia, A. J. Krueger, and J. R. Herman. (1996). Nimbus-7 Total Ozone Mapping Spectrometer (TOMS), Data Products User's Guide. NASA Reference Publication 1384, NASA/Goddard Space Flight Center, Greenbelt, MD 20771.

Newchurch, M. J., E.-S. Yang, D. M. Cunnold, G. C. Reinsel, J. M. Zawodny, and J. M. Russell III. (2003). Evidence for slowdown in stratospheric ozone loss: First stage of ozone recovery. J. Geophys. Res.. 108(D16), 4507, doi:10.1029/2003JD003471.

Reichrath, J. and B. Nürnberg. (2008). Solar UV-radiation, vitamin D and skin cancer surveillance in organ transplant recipients (OTRs). Adv Exp Med Biol. 624:203-14. Review.

Terrain Base The National Geophysical Data Center: TerrainBase, $\mathrm{ftp}: / /$ ncardata.ucar.edu/datasets/ds759.2/data/tbase.Z.

TOMS erythemal UV exposure dataset. README file (file erynotes.pdf). NASA Goddard Space Flight Center, Code 916, Greenbelt, MD 20770. ftp://jwocky.gsfc.nasa.gov/pub/eptoms/data/erynotes.pdf.

TOMS http://toms.gsfc.nasa.gov/

WMO. (1998). World Meteorological Organization. Scientific Assessment of Ozone Depletion: 1998. Global Ozone, Research and Monitoring Project Report. No. 44, Vol. I and II.

Woods, T. N., D. K. Prinz, G. J. Rottman, J. London, P. C. Crane, R. P. Cebula, E. Hilsenrath, G. E. Brueckner, M. D. Andrews, O. R.White, M. E. VanHoosier, L. E. Flyod, L. C. Herring, B. G. Knapp, C. K. Pankratz, and P. A. Reiser. (1996). Validation of the UARS Solar Ultraviolet Irradiances: Comparison with the ATLAS - 1, - 2 Measurements. J. Geophys. Res. 101, 9541-9569.

Zou, H. and Y. Gao. (1997). Vertical ozone profiles over Tibet Using Sage I and II data. Advances in Atmospheric Sciences, 14 4, pp. 515-524.

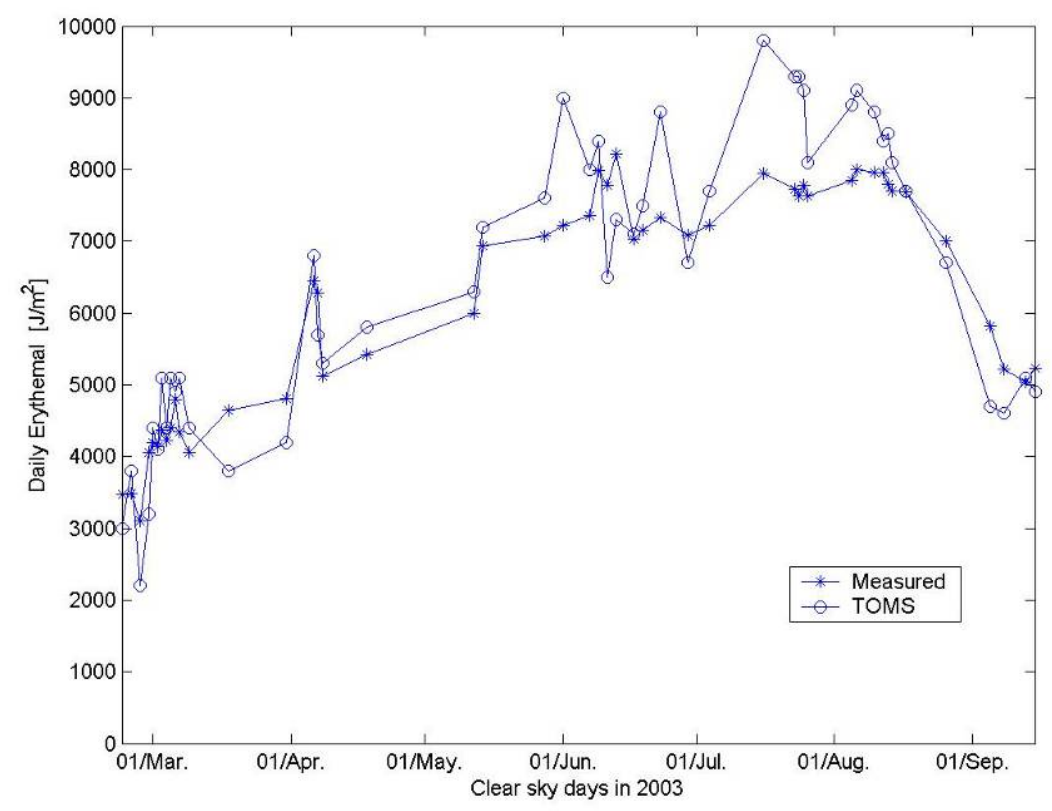

Figure 1. Comparisons between satellite-derived clear sky daily erythemal UV dose and corresponding value obtained from ground-based measurement for Lhasa in 2003 


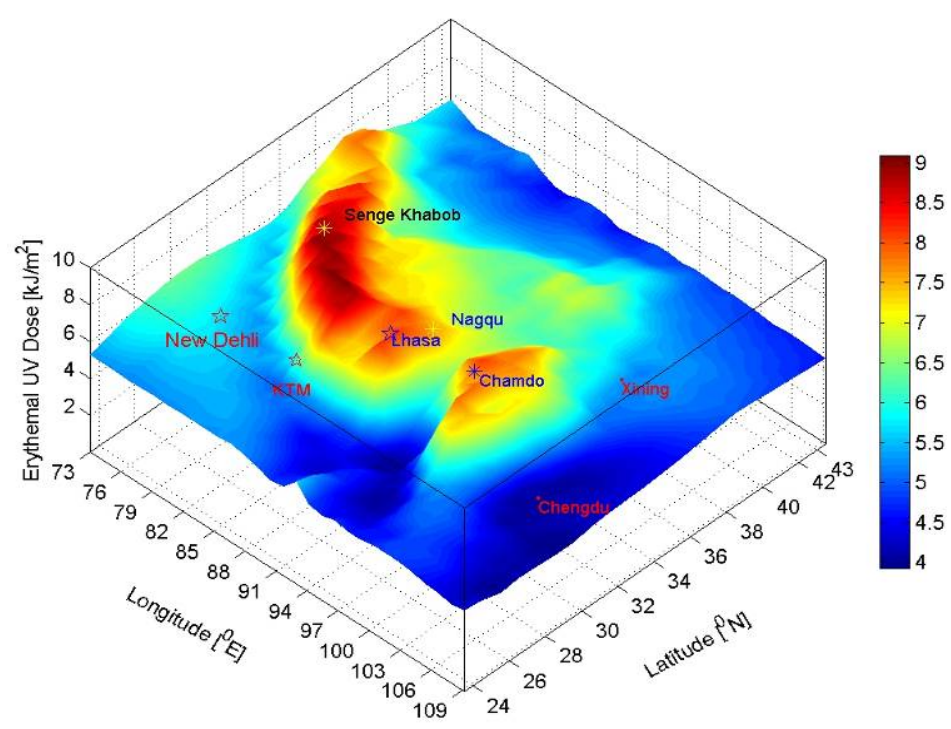

Figure 2. Spatial distribution (3D map) of the summer mean daily erythemal UV dose averaged for 21 years across the Tibetan Plateau and its neighboring areas. The different colors represent erythemal UV doses in $\mathrm{kJ} / \mathrm{m} 2$ as indicated by the color bar to the right

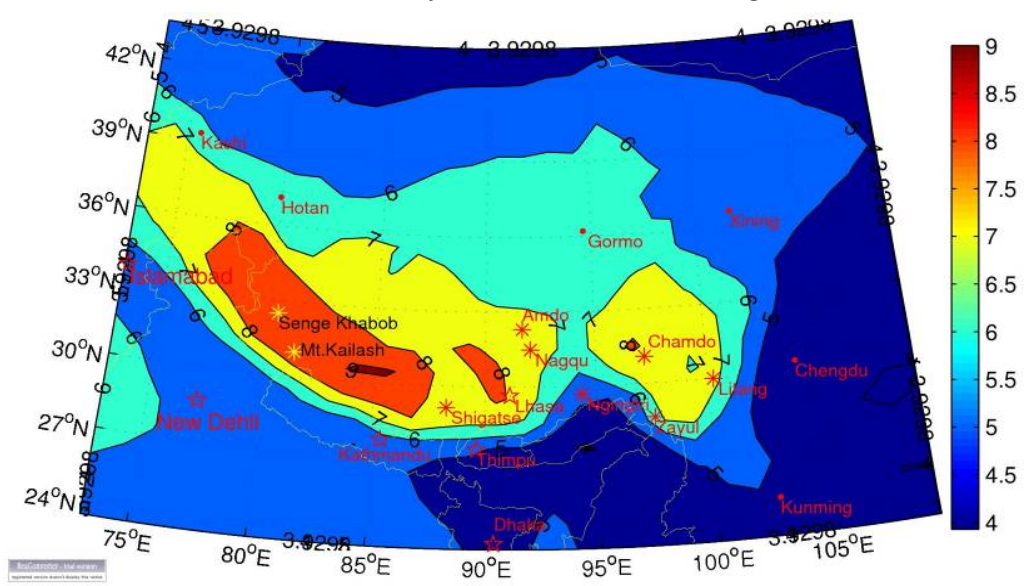

(a)

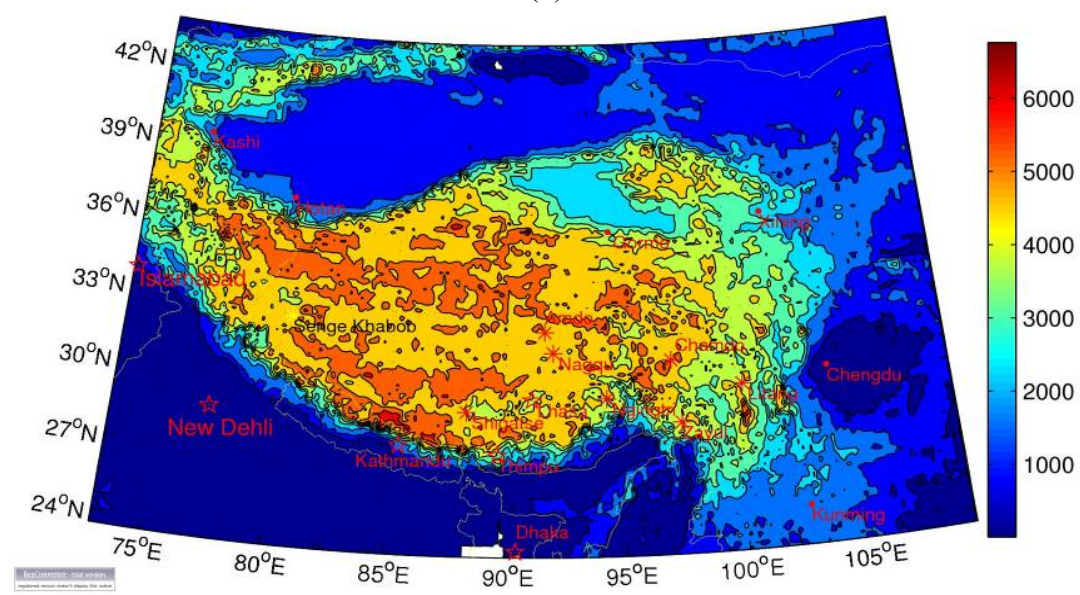

(b)

Figure 3. (a) Spatial distribution (2D map) of 21-year summer mean daily erythemal UV doses [kJ/m2] across the Tibetan Plateau and its neighbouring areas. (b) Color map of the elevation across the Tibetan Plateau and its vicinity 


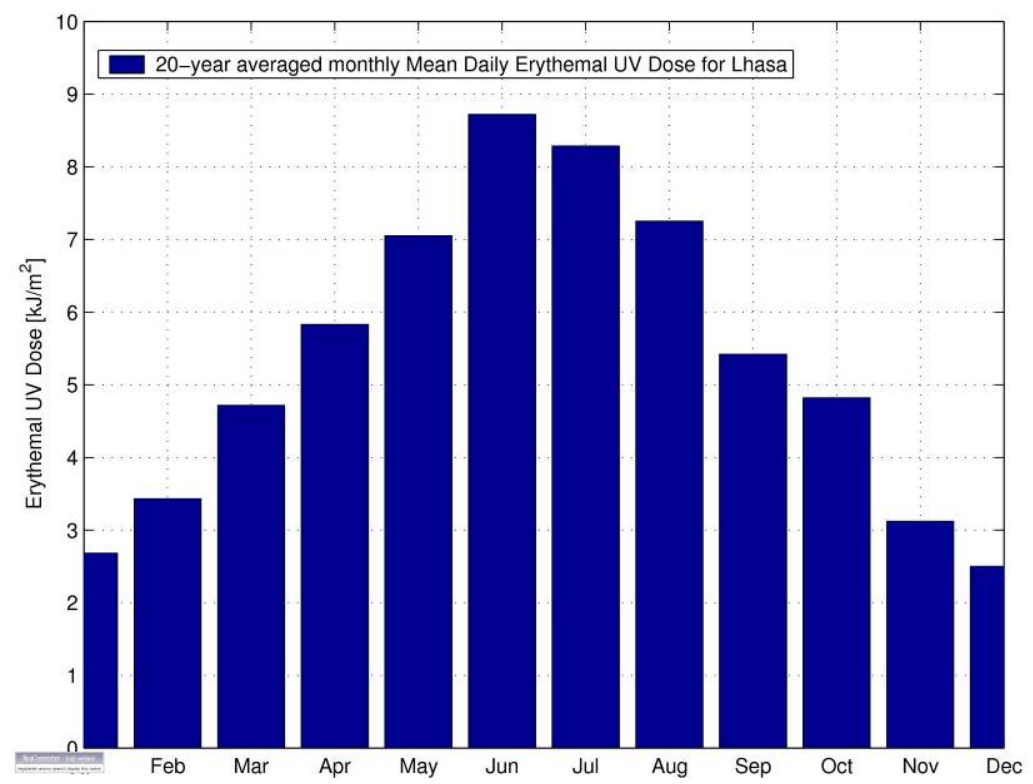

Figure 4 . The monthly mean daily erythemal UV dose averaged for 21 year for Lhasa.

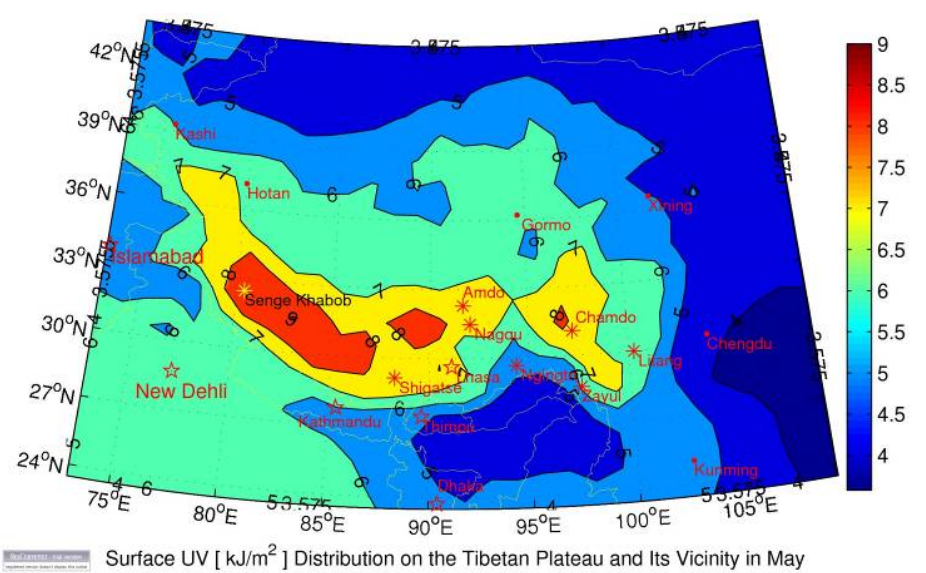

(May)

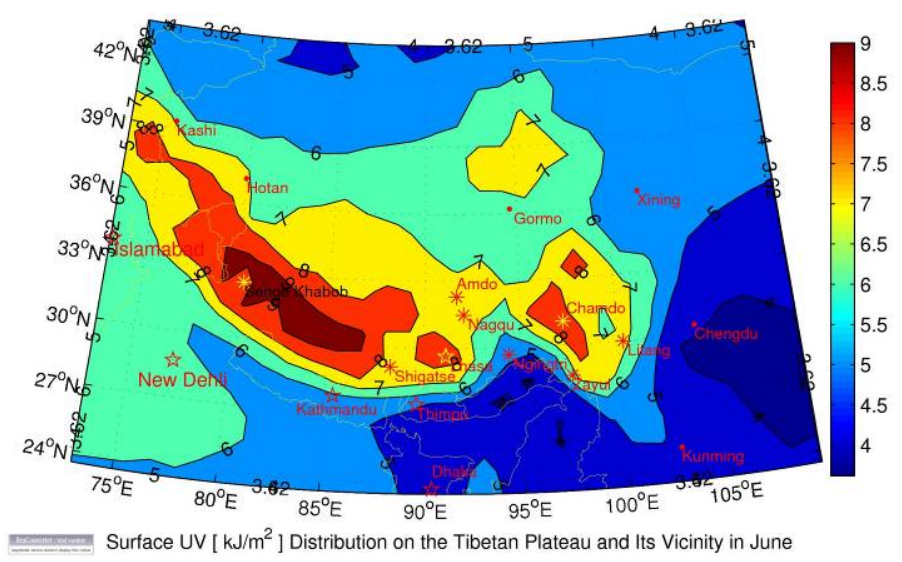

(June) 


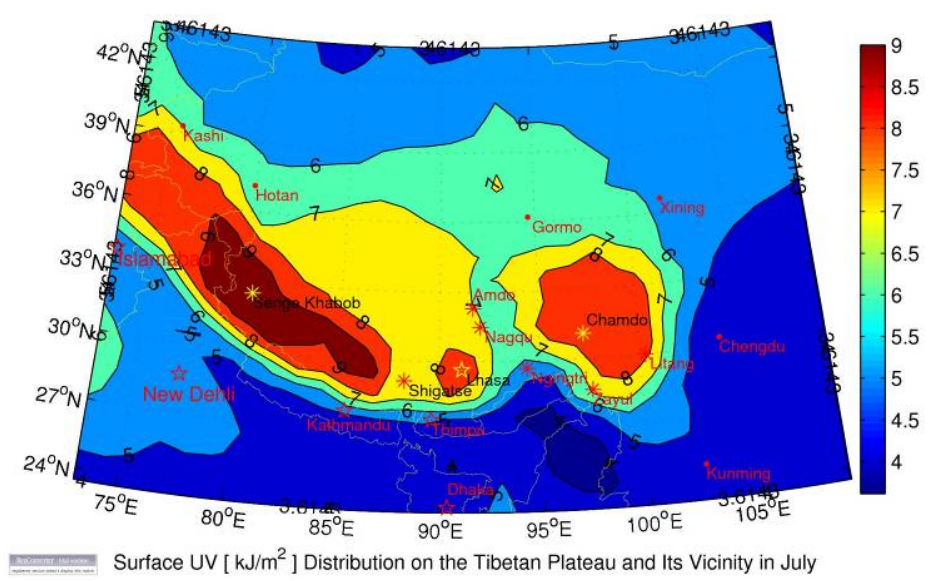

(July)

Figure 5. Monthly variations of the spatial distributions (2D map) of the daily erythemal UV dose over the Tibetan Plateau and in its neighbouring areas. The different colors in each map represent erythemal UV doses in $\mathrm{kJ} / \mathrm{m} 2$ as indicated by the color bar to the right

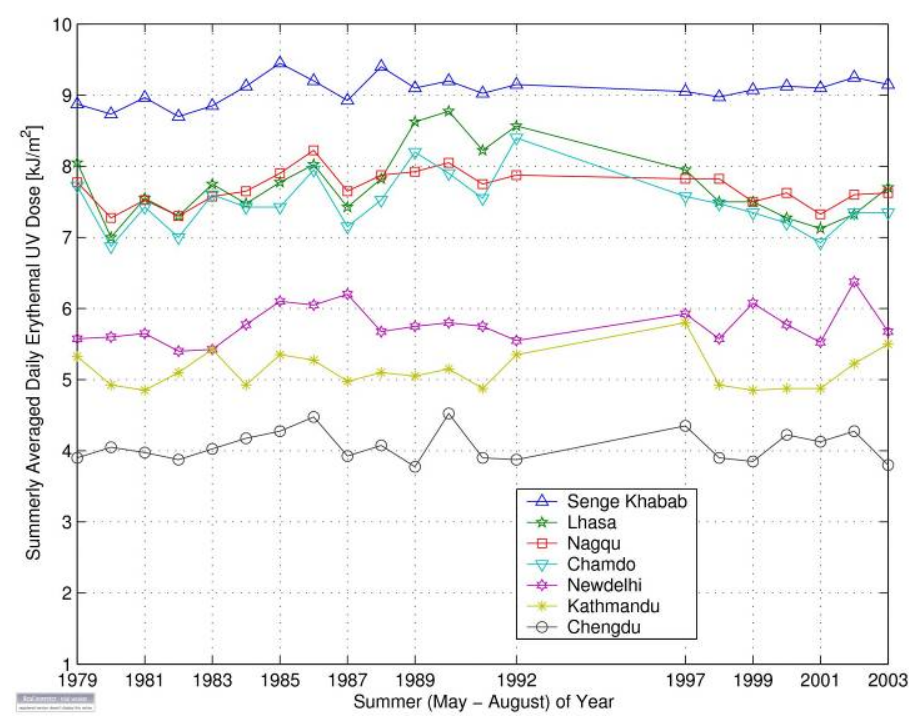

Figure 6. Long-term variations of the summer daily erythemal UV dose at selected towns on the Tibetan Plateau and in its neighbouring areas 